\title{
Interactions between Age, Stress and Insulin on Cognition: Implications for Alzheimer's Disease
}

\author{
Maite Solas', Bárbara Aisa', María C Mugueta², Joaquín Del Río', Rosa M Tordera' and María J Ramírez*' \\ 'Department of Pharmacology, School of Medicine, Center for Applied Medical Research, University of Navarra, Pamplona, Spain; ${ }^{2}$ Clinical \\ Chemistry Department, University Clinic of Navarra, University of Navarra, Pamplona, Spain
}

\begin{abstract}
There is much interest in understanding the mechanisms responsible for interactions among stress, aging, memory and Alzheimer's disease. Glucocorticoid secretion associated with early life stress may contribute to the variability of the aging process and to the development of neuro- and psychopathologies. Maternal separation (MS), a model of early life stress in which rats experience $3 \mathrm{~h}$ of daily separation from the dam during the first 3 weeks of life, was used to study the interactions between stress and aging. Young ( 3 months) MS rats showed an altered hypothalamic-pituitary-adrenal (HPA) axis reactivity, depressive-like behavior in the Porsolt swimming test and cognitive impairments in the Morris water maze and new object recognition test that persisted in aged ( 8 months) rats. Levels of insulin receptor, phosphorylated insulin receptor and markers of downstream signaling pathways (pAkt, pGSK3 $\beta$, pTau, and pERKI levels) were significantly decreased in aged rats. There was a significant decrease in pERK2 and in the plasticity marker ARC in MS aged rats compared with single MS or aged rats. It is interesting to note that there was a significant increase in the $C 99: C 83$ ratio, $A \beta$ levels, and BACEI levels the hippocampus of MS aged rats, suggesting that in aged rats subjected to early life stress, there was an increase in the amyloidogenic processing of amyloid precursor protein (APP). These results are integrated in a tentative mechanism through which aging interplay with stress to influence cognition as the basis of Alzheimer disease (AD). The present results may provide the proof-of-concept for the use of glucocorticoid-/insulin-related drugs in the treatment of AD.

Neuropsychopharmacology (2010) 35, 1664-1673; doi:I0.1038/npp.2010.13; published online 24 February 2010
\end{abstract}

Keywords: maternal separation; glucocorticoids; hippocampus; amyloidogenic route; ERK2; ARC

\section{INTRODUCTION}

Stress is believed to contribute to the variability of the aging process and to the development of age-related neuro- and psychopathologies (Heim and Nemeroff 1999; McEwen, 2002; Miller and O'Callaghan, 2005). Clinical data suggest that a stressful lifestyle can be a risk factor for Alzheimer's disease (AD) (Wilson et al, 2005) and stress-related psychiatric disorders (ie, major depression) have been identified as a risk for developing AD (Ownby et al, 2006). There is much interest, therefore, in understanding the mechanisms responsible for interactions among stress, aging and memory.

The effects of stress are thought to be mediated by the activation of the hypothalamic-pituitary-adrenal (HPA) axis, culminating in increased levels of glucocorticoids (Berton and Nestler, 2006). Aged rats and elderly humans show progressive loss of control of the HPA axis, resulting

*Correspondence: Dr MJ Ramírez, Department of Pharmacology, University of Navarra, Center for Applied Medical Research, C/ Irunlarrea, I, Pamplona, 31008, Spain, Tel: + 34948425 600,

Fax: + 34948425 649, E-mail: mariaja@unav.es

Received 23 September 2009; revised 22 January 2010; accepted 25 January 2010 in hypersecretion of glucocorticoids (Sapolsky et al, 1983; Born et al, 1995). Abnormal glucocorticoid secretion is thought to be involved in many aging-related diseases, including depression (Kendler et al, 1999), memory impairments (Sapolsky et al, 1986; Lupien et al, 1998; Aisa et al, 2007) and AD (Hartmann et al, 1997; Elgh et al, 2006). In experimental models of $\mathrm{AD}$, stress or glucocorticoids exacerbated AD-like neuropathology (Green et al, 2006; Jeong et al, 2006). Glucocorticoids not only have been suggested to contribute to age-related loss of neurons in the hippocampus of rats (Sapolsky, 1985), but also have been shown to potentiate hippocampal damage induced by various noxious insults (Sapolsky and Pulsinelli, 1985) including the amyloid $\beta(\mathrm{A} \beta)$ peptide, the main component of senile plaques in $\mathrm{AD}$ (Catania et al, 2009). Thus, a recently developed view suggests that hypercortisolemia, leading to hippocampal atrophy and further HPA axis disinhibition (ie, 'the glucocorticoid cascade hypothesis'), would initiate a chain of events, ultimately culminating in the development of lesions typical of AD (Dhikav and Anand, 2007). The mechanisms underlying the effects of altered glucocorticoid levels remain largely unknown. However, among them, it is worth mentioning the interrelation between glucocorticoids and insulin. Glucocorticoid excess results in insulin resistance by blunting insulin's 
action to suppress hepatic glucose production and stimulate peripheral glucose utilization (Amatruda et al, 1985). In addition to their effects on insulin sensitivity, glucocorticoids inhibit insulin secretion from pancreatic $\beta$-cells (Delaunay et al, 1997; Lambillotte et al, 1997). Glucocorticoids are elevated in rodents with experimental diabetes (Magariños and McEwen, 2000) and it has been suggested that cognitive impairment in diabetes may result from glucocorticoid-mediated deficits in neurogenesis and synaptic plasticity (Stranahan et al, 2008).

Maternal separation (MS) is an animal paradigm designed to mimic repeated exposure to stress during early life, resulting in animals with behavioral and neuroendocrine signs of elevated stress reactivity as adults (Lehmann and Feldon, 2000; Heim and Nemeroff, 2001; Aisa et al, 2007). The peak period of neurogenesis overlaps the stress hyporesponsive period (postnatal days, PND 4-14) in neonatal rats (Sapolsky and Meaney, 1986). Therefore, early stress, such as MS, could be interfering with the normal maturation of the hippocampal structure, which might ultimately lead to an increased vulnerability for psychiatric diseases. After the early developmental period, it is at present unknown how stress will have an effect on the aging process because of a lack of studies.

In this work we have studied the effects of an early life stress in aged rats. The main results found are that the interaction between stress and aging induced: (1) altered HPA axis reactivity, depressive-like behavior, cognitive impairments, intracellular insulin pathways alterations and plastic changes; and (2) promoted amyloid precursor protein (APP) processing towards the amyloidogenic pathway. These results provide a tentative mechanism through which aging interplay with stress to influence cognition, with a bias towards consideration of insulin-mediated mechanisms and neuroplastic events in the hippocampus, as the basis of $\mathrm{AD}$.

\section{MATERIALS AND METHODS}

\section{Animals}

All the experiments were carried out in strict compliance with the recommendations of the EU (DOCE L 358/1 18/2/1986) for the care and use of laboratory animals. Timed-pregnant Wistar rats were provided on gestation day 16 from Charles River Laboratories (Portage, MI, USA), individually housed in a temperature $\left(21 \pm 1^{\circ} \mathrm{C}\right)$ and humidity $(55 \pm 5 \%)$ controlled room on a 12 -h light-dark cycle (lights on at $0800 \mathrm{~h}$ ) with food and water freely available. Every effort was made to minimize the number of animals used and their suffering.

\section{MS Procedure}

On PND 2 (Aisa et al, 2007; Ladd et al, 2004), all pups were sexed and randomly assigned to the control group (pups manipulated to change the bedding in their cages once weekly), or the separation group (MS, pups separated daily from their dam as a litter for $3 \mathrm{~h}$ from PND 2-21 inclusive). Rats were weaned on PND 23 and only males were chosen for the present work. Subsequent experiments were carried out in young (60-75 days) and aged rats (18 months). Rats were not allowed to grow older as mortality increased significantly in the aged MS group. Animals from different litters were evenly spread over the different experimental groups. Animals were monthly weighted.

\section{Behavioral Test}

Behavioral experiments were conducted between $0900 \mathrm{~h}$ and $1300 \mathrm{~h}$. Observers were blind to the rearing condition. A different animal cohort was used for carrying out each of the different test.

\section{Locomotor Activity}

Locomotor activity was measured for $30 \mathrm{~min}$ in an open field $\left(65 \times 65 \mathrm{~cm}^{2}, 45 \mathrm{~cm}\right.$ height $)$ made of black wood, using a video-tracking system (Ethovision 3.0, Noldus Information Technology B.V., The Netherlands), in a softly illuminated room. Total path length $(\mathrm{cm})$ was analyzed.

\section{Forced Swimming Test}

The test was carried out as described (Porsolt et al, 1977). Briefly, two swimming sessions were conducted: an initial 15 -min pre-test followed $24 \mathrm{~h}$ later by a 5 -min test. Rats were placed individually in a vertical Plexiglas cylinder (height: $60 \mathrm{~cm}$, diameter: $30 \mathrm{~cm}$ ) filled with $45 \mathrm{~cm}$ of $23 \pm 1^{\circ} \mathrm{C}$ water. Immobility was considered as rats floating passively, making only small movements to keep its nose above the surface.

\section{Object Recognition Test (NORT)}

As previously described (Aisa et al, 2007), the open field consisted of a square open field $(65 \mathrm{~cm} \times 65 \mathrm{~cm} \times 45 \mathrm{~cm})$ made of black wood. On the previous day to the experiment, animals were familiarized with the square for $30 \mathrm{~min}$. During the first trial, two identical objects were placed within the chamber, and the rat was allowed to freely explore during $5 \mathrm{~min}$. Exploration was considered when the head of the rat was oriented toward the object with its nose within $2 \mathrm{~cm}$ of the object. An hour later a second trial took place, in which one object was replaced by another, and exploration was scored for $5 \mathrm{~min}$. Results were expressed as percentage of time spent with the new object with respect to the total exploration time (discrimination index).

\section{Morris Water Maze}

This memory task was carried out as previously described (Diez-Ariza et al, 2003). The maze consisted of a black circular tank ( $140 \mathrm{~cm}$ diameter $\times 55 \mathrm{~cm}$ high) and filled with water $\left(20-22^{\circ} \mathrm{C}\right)$. A black invisible platform, $10 \mathrm{~cm}$ diameter, was positioned $1 \mathrm{~cm}$ below the water surface. A video camera was set above the center of the pool and connected to a video traction system (EthoVision; Noldus Information Technology B.V.). The pool was surrounded by white curtains marked with black geometric paintings, so as to enable the animals to learn the platform location. On the first day, each rat becomes habituated to the training environment for $60 \mathrm{~s}$. In the acquisition phase (days 2-3), rats performed 6 training trials per day $(120 \mathrm{~s}$ each) with the escape platform in a fixed position. Time spent to reach the 
platform (latency), the swim path length (distance swam), and the swim speed $(\mathrm{cm} / \mathrm{s})$ were recorded. The results on time to reach the platform are not shown as, in all cases, parallel with distances swam. On day 4, (retention phase) a single transfer test was carried out, in which the platform was removed from the tank. The animal was allowed to swim for $60 \mathrm{~s}$ in search of the platform. The distance swam in the quadrant where the platform was previously located was measured.

\section{Biochemical Measurements}

Tissue and blood collection. Fasting rats were killed by decapitation between $0800-1000 \mathrm{~h}$. Brains were removed and dissected on ice to obtain the hippocampus or frozen immediately and stored at $-80{ }^{\circ} \mathrm{C}$ until sectioning. Trunk blood was collected into EDTA tubes, centrifuged at $1250 \mathrm{~g}$ $\left(15 \mathrm{~min}, 4^{\circ} \mathrm{C}\right)$, and plasma was frozen.

Plasma corticosterone, insulin and IGF1 determinations. Plasma corticosterone $(50 \mu \mathrm{l})$ was determined using a commercially available solid-phase ${ }^{125} \mathrm{I}$ radioimmunoassay kit (Coat-a-Count, Siemens, USA). Insulin was measured in $10 \mu \mathrm{l}$ plasma samples using the Sensitive Rat Insulin Enzyme Immunoassay Kit (EZRMI-13K, Millipore, Billerica, MA, USA). IGF1 levels were determined using a commercially available solid-phase ${ }^{125}$ I radioimmunoassay kit (DSL2900, Diagnostic System Laboratories, TX, USA).

Western blotting. Assays were carried out as described in Table 1. Immunopositive bands were visualized using an enhanced chemiluminescense western blotting-detection reagent (ECL; Amersham, Buckinghamsire, England). The optical density (O.D.) of reactive bands visible on X-ray film was determined densitometrically. $\beta$-actin or $\alpha$-tubulin was used as internal control. Results were expressed as percentage of O.D. values of control young rats.

A $\beta$ levels. A $\beta 1-42$ levels were determined using a commercially available high-sensitive ELISA kit (Wako Pure Chemical Industries, Tokyo, Japan) following manufacturer instructions.

In situ hybridization for BDNF and activity-regulated cytoskeletal-associated protein (ARC) mRNA. Coronal brain sections containing the hippocampus ( $15 \mu \mathrm{m}$ thick) were cut at the level of $-3.3 \mathrm{~mm}$ (relative to the bregma) according to the atlas of Paxinos and Watson (1982). The oligonucleotides used were: $5^{\prime}$-AGTTCCAGTGCCTTTTGTC TATGCCCCTGCAGCCTTTGGTGTAAC- $3^{\prime}$ for BDNF and 5'-CTTGGTTGCCCATCCTCACCTGGCACCCAAGACTGGT ATTGCTGA-3' for ARC, both from Sigma Genosis, UK. Probes were $3^{\prime}$-tail labeled with $\alpha \mathrm{S}\left[{ }^{35} \mathrm{~S}\right] \mathrm{dATP}$, specific activity $>1000 \mathrm{Ci} / \mathrm{mmol}$ (GE Healthcare Biosciences, Europe). Negative controls including sense oligonucleotides showed minimal background signals. Sections were exposed to Biomax MR film (Kodak) for 3 days (BDNF) or 3 weeks (ARC). The relative abundance mRNA in each region was determined by densitometric quantification of autoradiograms using an image analysis system (Scion Image, Scion Corporation, USA) correcting for non-specific signals. O.D. values were calibrated to ${ }^{35} \mathrm{~S}$ tissue equivalents using ${ }^{14} \mathrm{C}$

Table I Conditions used in western blotting experiments

\begin{tabular}{|c|c|c|c|}
\hline Protein & Homogenization buffer & SDS-polyacrylamide gel & Primary antibody (dilution) \\
\hline IDE & Buffer I & $13 \%$ & Anti-IDE $(1: 1000)^{a}$ \\
\hline pAkt & Buffer I & $13 \%$ & Anti-pAkt Ser473 $(1: 1000)^{b}$ \\
\hline Total Akt & Buffer I & $13 \%$ & Anti-Akt $(1: 1000)^{b}$ \\
\hline pGSK3 $\beta$ & Buffer I & $13 \%$ & Anti-pGSK3 $\beta$ Ser $9(1: 1000)^{b}$ \\
\hline Total GSK3 $\beta$ & Buffer I & $13 \%$ & Anti pGSK3 $\beta(1$ : I000) \\
\hline pTau & Buffer I & $13 \%$ & Anti-pTau Ser202/Thr205 AT8 (I : I000) \\
\hline Total Tau & Buffer I & $13 \%$ & Anti-Tau T46 (I : 3000) ${ }^{\mathrm{d}}$ \\
\hline GR & Buffer I & $8 \%$ & Anti-GR $(1: 2000)^{\mathrm{e}}$ \\
\hline $\mathbb{R}$ & Buffer 2 & $8 \%$ & Anti-IR $(1: 500)^{b}$ \\
\hline
\end{tabular}

Abbreviations: APP C-terminal, APP carboxy-terminal fragments (C83 and C99); GR, glucocorticoid receptor; IDE, insulin degrading enzyme; IR, insulin receptor

Buffer I: $50 \mathrm{mmol} / / \mathrm{Tris}-\mathrm{HCl}, \mathrm{pH}$ 8; $150 \mathrm{mmol} / / \mathrm{NaCl}, 2 \mathrm{mmol} / \mathrm{I} \mathrm{EDTA}, 2 \mathrm{mmol} / / \mathrm{EGTA}, 0.5 \mathrm{mmol} / /$ phenylmethanesulfonyl fluoride, I mmol// sodium vanadate,

$10 \mathrm{mg} / \mathrm{ml}$ leupeptin, and I\% Nonidet P-40, I : 100 of phosphatases inhibitors cocktail set II (Calbiochem, Darmstadt, Germany); buffer 2: SDS 2\%, Tris-HCl

( 10 mM, pH 7.4), protease inhibitors (Complete Protease Inhibitor Cocktail, Roche), and phosphatase inhibitors (0.I mM Na3VO4, I mM NaF).

Source of antibodies:

aAbcam, Cambridge, MA, USA.

${ }^{\mathrm{b} C e l l}$ Signaling Technology, Beverly, MA, USA.

'Pierce, Rockford, IL, USA.

${ }^{\mathrm{d}}$ Sigma-Aldrich, St. Louis, MO, USA.

eSanta Cruz Biotechnology, CA. 
microascales (Amersham, UK) and the appropriate conversion factor. Densitometric values from three sections of each animal were averaged and expressed as nCi/g tissue.

Data analysis. Data were analyzed by SPSS for Windows, release 15.0 and normality was checked by Shapiro-Wilks's test $(p<0.05)$. In the acquisition phase of the Morris water maze, over-all treatment effects were examined by two-way repeated measures ANOVA (rearing $\times$ trial). Differences between trials within groups were analyzed using a factorial ANOVA with replicates. Data in the retention phase were analyzed with one-way ANOVA. Neurochemical data was analyzed by two-way analysis (rearing $\times$ age) of variance ANOVA. Post hoc comparisons were conducted, if appropriate, using Tukey's protected least significance test. Data are presented as mean \pm SEM. The level of significance for all analyses testing was set at $p<0.05$.

\section{RESULTS}

\section{Overall Effects of Stress and Age on Weight Gain,} Locomotor Activity, and Depression-Like Behavior

As shown in Table 2, there was a main effect of age in weight gain (two-way ANOVA, $\mathrm{F}_{1,60}=180.673, p<0.001 ; n=10-22$ ) and locomotor activity $\left(\mathrm{F}_{1,82}=330.239, p<0.001 ; n=10-17\right)$ (Table 2).

In the forced swimming test, there was an increased immobility time, indicative of depressive-like behavior, in both young and aged MS rats (two-way ANOVA, main effect of rearing, $\mathrm{F}_{1,82}=17.217, p<0.001 ; n=10-17$ ) (Table 2).

\section{Effects of Age and MS on Cognition}

In the acquisition phase of Morris water maze, distance swam to reach the platform improved significantly over trials in all groups (factorial ANOVA with replicates) and no significant effect of rearing or age was found. However, in the retention phase, both rearing $\left(\mathrm{F}_{1,55}=7.199, p<0.05 ; n=8-21\right)$ and age $\left(\mathrm{F}_{1,55}=14.220, p<0.001 ; n=8-21\right)$ produced a statistically significant decrease in distance swam in the quadrant were the platform used to be located, indicative of a memory impairment (Figure 1a). Swim speed was not affected by rearing or age.

A two-way ANOVA indicated a main effect of rearing in the NORT, and MS rats showed a learning impairment $\left(\mathrm{F}_{1,58}=8.964, p<0.01 ; n=12-18\right)$ as the discrimination index was significantly lower (Figure $1 \mathrm{~b}$ ).

\section{Age and MS Interact to Affect HPA Axis}

There was a significant rearing $\times$ age interaction in plasma corticosterone levels (two-way ANOVA, $\mathrm{F}_{1,50}=4.689, p<0.05$; $n=8-19)$. Further analysis showed a significant increase in corticosterone levels in young MS rats (Student's $t$-test; $p<0.05$ ) and almost significant effect in aged MS rats (Student's $t$-test; $p=0.06)$ compared with young controls (Table 2 ).

Hippocampal glucocorticoid receptor density mediates the glucocorticoid negative feedback to modulate HPA axis activity. Statistical analysis indicates a significant interaction between rearing and age $\left(\mathrm{F}_{1,34}=11.671, p<0.01\right.$; $n=8-10)$. Post-hoc analysis showed that, compared with young controls, there was a significant decrease in glucocorticoid receptor levels in young MS, aged controls and aged MS (Student's $t$-test; $p<0.001$, in all cases). Glucocorticoid receptors were also decreased when comparing young and aged MS rats (Student's $t$-test; $p<0.05$ ) (Table 2).

\section{Age and MS Interact to Affect Insulin Levels, IDE and Intracellular Insulin Pathways}

There was an interaction $\left(\mathrm{F}_{1,39}=3.776, p<0.05 ; n=10\right)$ between rearing and age in fasting plasma insulin levels.

Table 2 Effects of age and maternal separation (MS) on weight, locomotor activity, depressive-like behaviour, markers of HPA axis activity, and insulin pathways

\begin{tabular}{|c|c|c|c|c|}
\hline & \multicolumn{2}{|c|}{ Young (3 months) } & \multicolumn{2}{|c|}{ Aged (18 months) } \\
\hline & Control & MS & Control & MS \\
\hline Locomotor activity $(\mathrm{cm})$ & $6910.08 \pm 300.92$ & $7704.13 \pm 378.52$ & $2333.15 \pm 172.17^{\mathrm{a}}$ & $2536.27 \pm 553.46^{\mathrm{a}}$ \\
\hline Porsolt, immobility time (s) & $72.50 \pm 10.67$ & $|1| .00 \pm\left. 5.9\right|^{\mathrm{b}}$ & $55.92 \pm 6.49$ & $95.76 \pm 9.56^{b}$ \\
\hline Corticosterone $(\mathrm{ng} / \mathrm{ml})$ & $392.70 \pm 51.08$ & $579.41 \pm 25.16^{c}$ & $566.65 \pm 58.93$ & $525.49 \pm 39.86$ \\
\hline Insulin (ng/ml) & $3.74 \pm 0.45$ & $2.27 \pm 0.40^{c}$ & $1.98 \pm 0.26^{c}$ & $1.81 \pm 0.26^{\mathrm{d}}$ \\
\hline IGFI (ng/ml) & $1321.70 \pm 50.50$ & $1274.90 \pm 35.87$ & $|104.1| \pm 47.33^{\mathrm{a}}$ & $967.82 \pm 52.24^{\mathrm{a}}$ \\
\hline IDE (\% O.D.) & $100.00 \pm 10.68$ & $64.96 \pm 9.43^{c}$ & $51.76 \pm 6.09^{d}$ & $71.94 \pm 10.5 \mid$ \\
\hline Total IR (\% O.D.) & $100.00 \pm 4.48$ & $92.49 \pm 6.71$ & $54.98 \pm 6.73^{\mathrm{a}}$ & $51.52 \pm 8.78^{\mathrm{a}}$ \\
\hline $\mathrm{plR}(\%$ O.D.) & $100.00 \pm 12.43$ & $86.09 \pm 10.97$ & $39.82 \pm 1.68^{\mathrm{a}}$ & $17.55 \pm 0.79^{a}$ \\
\hline
\end{tabular}

Abbreviations: HPA, hypothalamic-pituitary-adrenal; IDE, insulin degrading enzyme; IGFI, insulin-like growth factor I; IR, insulin receptor; O.D., optical density. $N=10$ (control and MS young rats), 18 (control aged rats), and 22 (MS aged rats).

${ }^{a} p<0.001$ main effect of age, two-way ANOVA (rearing $\times$ age)

${ }^{b} p<0.001$ main effect of rearing, two-way ANOVA (rearing $\times$ age).

'Two-way ANOVA, significant interaction (rearing $\times$ age), $p<0.05$ vs control young ( 3 months) rats.

${ }^{\mathrm{d}}$ Two-way ANOVA, significant interaction (rearing $\times$ age) $p<0.00$ I vs control young (3 months) rats.

e $p<0.05$ vs MS young (3 months) rats. 

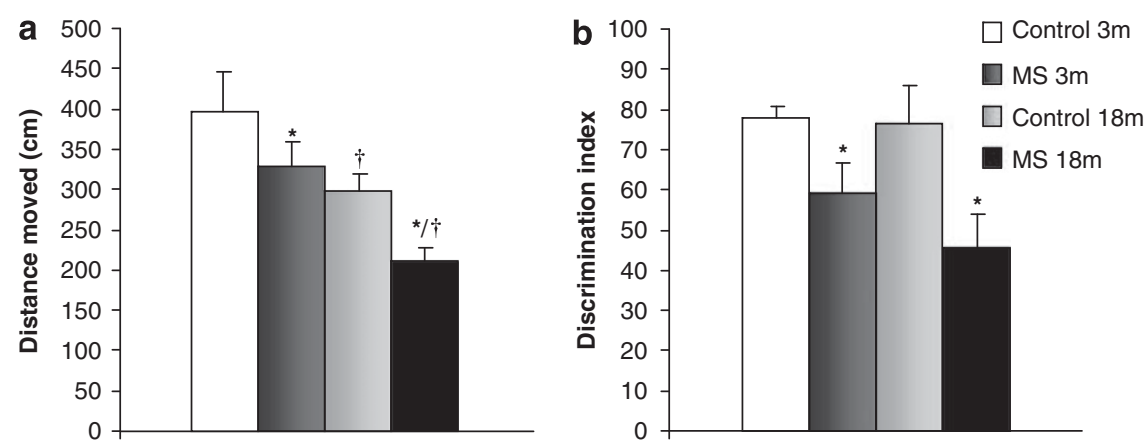

Figure I Effects of age and maternal separation (MS) on cognition. (a) Retention phase of the Morris water maze, data are presented as distance swam in the quadrant where platform used to be located. There was a main effect of rearing $\left(F_{1,55}=7.199, p<0.05\right)$ and age $\left(F_{1,55}=\mid 4.220\right.$, $\left.p<0.00 I\right)$. $(b) N e w$ object recognition test, data presented as discrimination index: time exploring the new object/total exploration time $\times 100$. There was a main effect of rearing $\left(F_{1,58}=8.964, p<0.01\right) .3 \mathrm{~m}: 3$ months, young rats; and $18 \mathrm{~m}: 18$ months, aged rats $* p<0.001$ main effect of rearing, ${ }^{\dagger} p<0.05$ or better, main effect of age.

Further analysis showed that there was a significant decrease in insulin levels in MS young, aged and MS aged rats (Student's $t$-test; $p<0.05$ or $p<0.01$ ). Levels of insulinlike growth factor 1 (IGF1) were only affected by age $\left(\mathrm{F}_{1,39}=22.346, p<0.001 ; n=10\right)$ (Table 2).

There was a significant interaction $\left(\mathrm{F}_{1,37}=8.127, p<0.01\right.$; $n=10-11)$ between rearing and age in hippocampal IDE levels. Further analysis revealed that both the MS procedure (control vs MS rats, Student's $t$-test; $p<0.05$ ) or age (control $v s$ aged rats, Student's $t$-test; $p<0.001)$ produced significant decreases in IDE levels (Table 2).

There was a main effect of age in levels of insulin receptors (IRs) $\left(\mathrm{F}_{1,35}=23.420, p<0.001 ; n=8-10\right)$ and IR phosphorylation $\quad\left(\mathrm{F}_{1,17}=103.992, \quad p<0.001 ; \quad n=4-5\right)$ (Table 2). When studying the insulin pathways, it was found that there was a main effect of age in levels of phosphorylated Akt (pAkt) (Ser473) normalized to total Akt $\left(\mathrm{F}_{1,41}=9.606, p<0.01 ; n=8-12\right)$ (Figure $\left.2 \mathrm{a}\right)$, pGSK3 $\beta$ (Ser9) normalized to total GSK3 $\beta\left(\mathrm{F}_{1,32}=33.318, p<0.001 ; n=\right.$ 6-10) (Figure 2b), pTau (Ser202/Thr205) normalized to total Tau $\left(\mathrm{F}_{1,35}=25.622, p<0.001 ; n=8-10\right)$ (Figure $2 \mathrm{c}$ ) and pERK1 (Thr202/Tyr204) levels normalized to total ERK1 $\left(\mathrm{F}_{1,33}=20.429, p<0.001 ; n=6-10\right)$ (Figure 2d). Consistent with a post-transcriptional regulation of these enzymes, total Akt, GSK3 $\beta$, Tau, and ERK1 protein levels, normalized using actin, remained unaltered. It is interesting to note that there was an interaction (rearing $\times$ age $)\left(\mathrm{F}_{1,35}=\right.$ 6.054, $p<0.05, n=8-10$ ) in pERK2 (Thr202/Tyr204) levels normalized to total ERK2. Further analysis showed a significant decrease in pERK2 in aged MS compared with young MS or aged rats (Student's $t$-test; $p<0.05$ in both cases) (Figure 2d). Total ERK2 levels normalized using actin did not show significant changes.

\section{Neonatal Stress Favors the Amyloidogenic Processing of APP in Aged Rats}

As depicted in Figure 3a, APP protein levels were not altered by rearing condition or age (two-way ANOVA, $\mathrm{F}_{1,31}=2.030$, $p=0.165 ; n=8)$. When analyzing the amyloidogenic route, significant increases in the C99: C83 ratio were found associated to rearing $\left(\mathrm{F}_{1,26}=4.164, p<0.05 ; n=7-8\right)$ or age $\left(\mathrm{F}_{1,26}=5.158, p<0.05 ; n=7-8\right)$ (Figure $\left.3 \mathrm{a}\right) . \mathrm{A} \beta$ levels were also significantly increased by age $\left(\mathrm{F}_{1,22}=11.116, p<0.01\right.$; $n=6)$ and rearing $\left(\mathrm{F}_{1,22}=5.723, p<0.05 ; n=6\right)$ (Figure $3 \mathrm{~b}$ ). Regarding BACE1 levels, there was a main effect of rearing $\left(\mathrm{F}_{1,22}=7.390, p<0.05 ; n=6\right)$ and age $\left(\mathrm{F}_{1,22}=10.380\right.$, $p<0.01 ; n=6$ ) (Figure $3 c$ ).

\section{Effect of Age and MS on Synaptic Plasticity}

Significant decreases in BDNF mRNA density were found in the dentate gyrus (DG) $\left(\mathrm{F}_{1,15}=14.086, p<0.01 ; n=4-5\right)$ and $\mathrm{CA} 3$ regions $\left(\mathrm{F}_{1,15}=23.079, p<0.01 ; n=4-5\right)$ of the hippocampus of MS rats compared with control rats. In the CA1 region there was an interaction rearing $\times$ age $\left(\mathrm{F}_{1,14}=7.141, p<0.05\right)$. Post-hoc analysis showed that MS produced a significant decrease of BDNF expression in young rats (Student's $t$-test; $p<0.01 ; n=4$ ) and almost significant effect in aged rats (Student's $t$-test; $p=0.08$; $n=4$ ) (Figure 4a).

Regarding ARC mRNA levels, there was a main affect of age and rearing in the DG $\left(\mathrm{F}_{1,15}=121.767, p<0.001\right.$; $n=4-5$; and $\mathrm{F}_{1,15}=386.446, p<0.001 ; n=4-5$, respectively) and $\mathrm{CA} 3$ region of the hippocampus $\left(\mathrm{F}_{1,15}=89.481\right.$, $p<0.001 ; n=4-5$; and $\mathrm{F}_{1,15}=212.861, p<0.001 ; n=4-5$, respectively). In the $\mathrm{CA} 1$ region, there was an interaction (rearing $\times$ age $)\left(\mathrm{F}_{1,15}=10.448, p<0.01 ; n=4-5\right)$. Further analysis showed significant decreases in ARC mRNA expression in MS young (Student's $t$-test, $p<0.001 ; n=4$ ), aged (Student's $t$-test, $p<0.001 ; n=4-5$ ), and MS-aged rats (Student's $t$-test; $p<0.001 ; n=4-5$ ) compared to control young rats, and further decreases in MS aged rats compared with MS young rats (Student's $t$-test; $p<0.001 ; n=4$ ).

\section{DISCUSSION}

The MS model in rat is considered nowadays as a robust model of enhanced stress responsiveness (Ladd et al, 2000; Lehmann and Feldon, 2000; Oitzl et al, 2000; Aisa et al, 2007). Even though several studies have focus in the characterization of the MS model in adult animals, little work has been done on how neonatal stress would impact the aging process. In our hands, not only the behavioral (depression-like) effects of MS persisted until senescence 

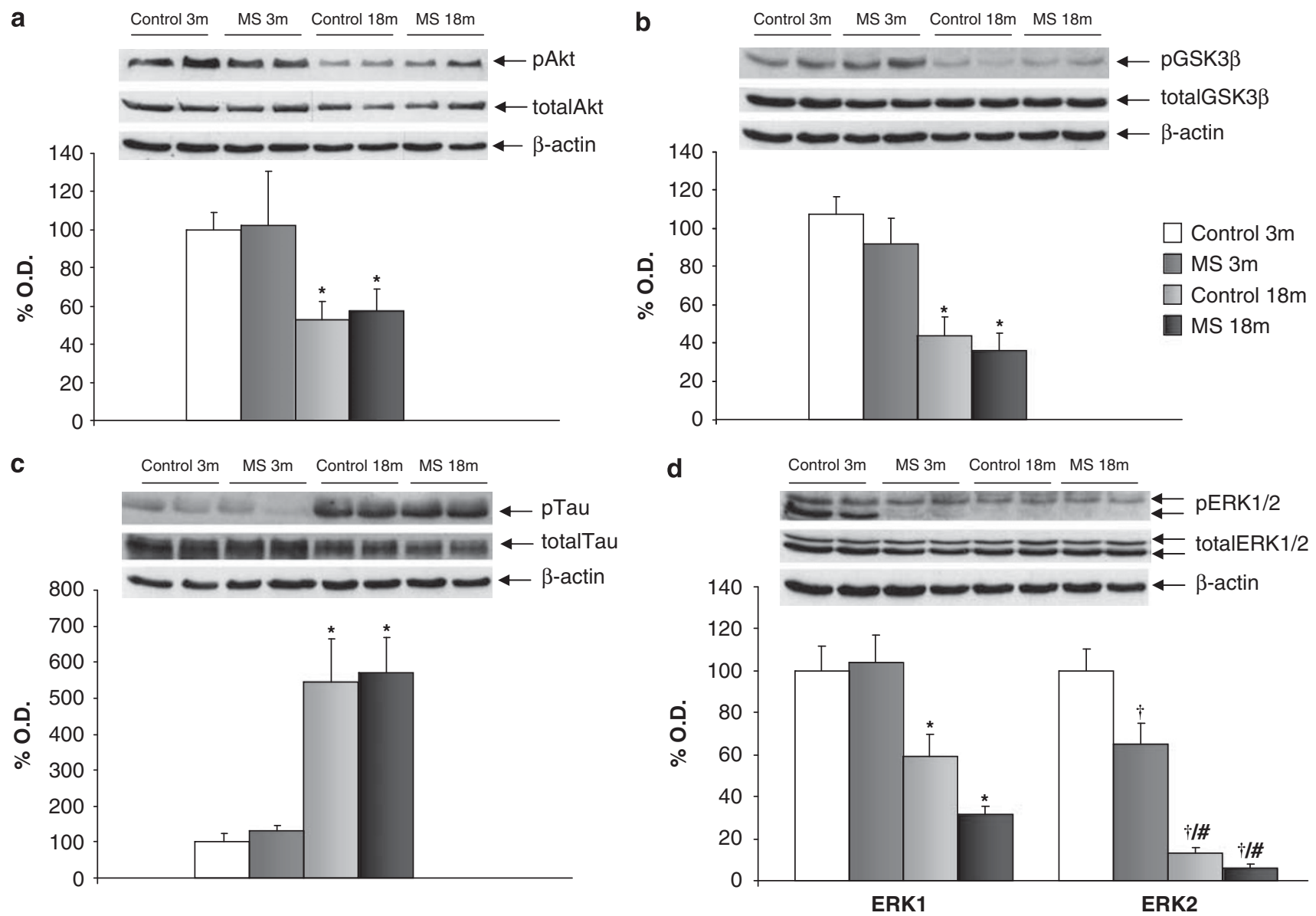

Figure 2 Age and maternal separation (MS) interact to affect insulin levels and intracellular insulin pathways. (a) Phosphorylated Akt levels (active form of the enzyme, $60 \mathrm{kDa}$ ) normalized to total Akt, main effect of age $\left(F_{1,41}=9.606, p<0.01 ; n=8-12\right)$; (b) phosphorylated (inactive) GSK3 $\beta$ levels (46 kDa) normalized to total GSK3 $\beta$, main effect of age $\left(F_{1,32}=33.318, p<0.001 ; n=6-10\right)$; (c) Phosphorylated Tau levels (40-50 kDa) normalized to total Tau, main effect of age $\left(F_{1,35}=25.622, p<0.00 I ; n=8-10\right)$; (d) Phosphorylated (active) ERKI (44 kDa) normalized to total ERKI, main effect of age $\left(F_{1,33}=20.429, p<0.00 \mathrm{I} ; n=6-10\right)$ and phosphorylated (active) ERK2 levels $(42 \mathrm{kDa})$ normalized to total ERK2, interaction $($ rearing $\times$ age $)\left(F_{1,35}=6.054\right.$, $p<0.05)$. Figure shows percentage of optical density (O.D.) values of control young rats and representative picture of the blotting. No differences were found in the non-phosphorylated (total) levels of the enzymes. $3 \mathrm{~m}: 3$ months, young rats; and $18 \mathrm{~m}$ : I 8 months, aged rats. $* p<0.01$ or better, main effect of age. ${ }^{\dagger} p<0.05$ or better vs control young rats, ${ }^{\#} p<0.05$ vs MS young rats.

but also our findings suggest that neonatal stress may have accelerated cognitive decline, at least in the Morris water maze, a hippocampal-dependant task. The results found on the NORT, together with the fact that the hippocampus is only minimally involved in memory for objects (Brown and Aggleton, 2001), would support the notion that the interaction age-stress in memory deficits mainly has its anatomical substrate on the hippocampus. It is worth mentioning that even though aged rats seem to have a decreased activity in the open field test, other measurements of locomotor activity, such as swim speed in the Morris water maze or total exploration time in the first exposure to objects in the NORT, did not differ among groups.

\section{Age and MS Interact to Affect Insulin Pathways}

In accordance to our data, it has been described that alterations in behavior and cognition associated with MS stress are related to increased levels of glucocorticoids
(Aisa et al, 2007; Wigger and Neumann, 1999). Aging 'per se' is also accompanied by a progressive increase in basal corticosterone levels in rats (Sapolsky et al, 1983; Sapolsky et al, 1986; Hauger et al, 1994). As described in the Introduction section, the effect of glucocortiocoids in vivo appears to include a decrease in circulating insulin levels. Even though the reduced peripheral levels of insulin found in this study do not necessarily imply equally reduced insulin levels in the brain (ie, the low levels of IDE in the hippocampus induced by either stress or ageing could lead to locally slower insulin degradation), the reduced IR expression and phosphorylation status suggest that effects dependent on intracellular insulin pathways activity could be inhibited in MS aged rats. In addition, it could be excluded that IGF1, known to be closely related to insulin and share similar cellular signaling events (Dupont and LeRoith, 2001) could compensate for insulin decreased levels.

The insulin signal transduction cascade of the PI3K/Akt/ GSK3 $\beta$ pathway promotes neuronal survival by directly inactivating the proapoptotic machinery. It is interesting to 
a
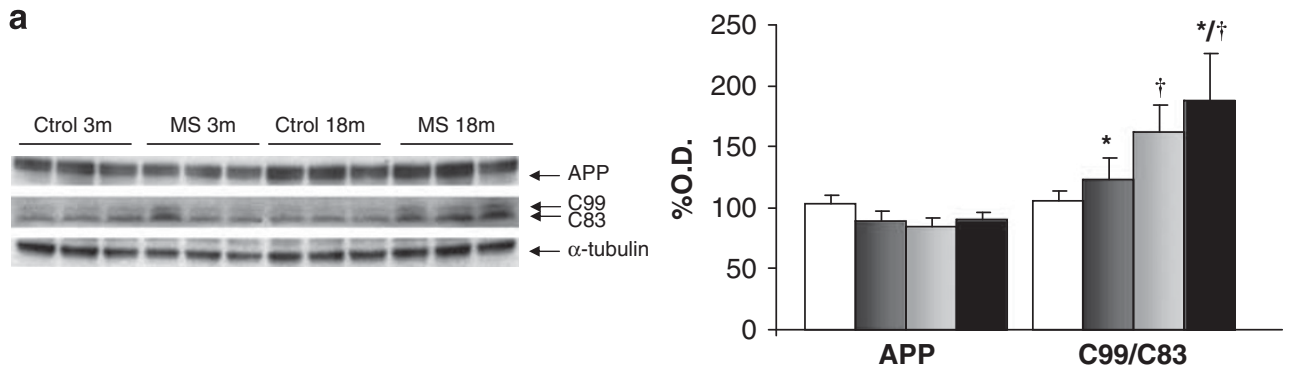

b
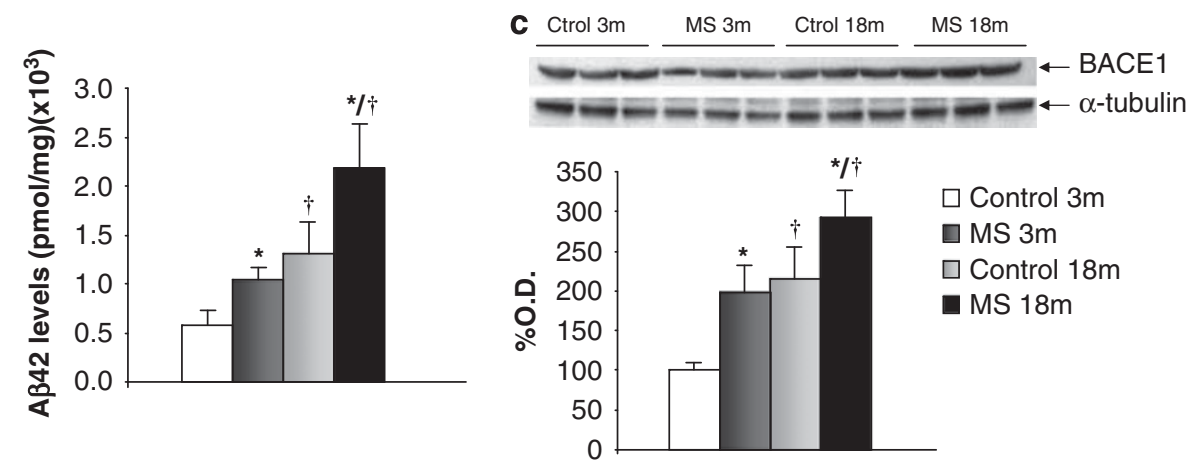

Figure 3 Neonatal stress favors the amyloidogenic processing of amyloid precursor protein (APP) in aged rats. (a) APP protein (I05 $\mathrm{kDa}$ ) levels (no effects of age or rearing) and C99: C83 $(10 \mathrm{kDa})$ ratio, main effect of rearing $\left(F_{1,26}=4.164, p<0.05\right)$ and age $\left(F_{1,26}=5.158, p<0.05\right)$. (b) $A \beta$ levels $(p m o l /$ $\mathrm{mg})\left(\times 10^{8}\right)$, main effect of age $\left(F_{1,22}=11.116, p<0.01 ; n=6\right)$, main effect of rearing $\left(F_{1,22}=5.723, p<0.05 ; n=6\right)$. (c) BACEI (70 kDa) levels, main effect of rearing $\left(F_{1,22}=7.390, p<0.05\right)$ and age $\left(F_{1,22}=10.380, p<0.01\right)$. a and $c$ show percentage of optical density $(O . D$. $)$ values of control young rats and representative picture of the blotting. 3 m: 3 months, young rats; and 18 m: 18 months, aged rats; MS: maternal separation rats. *p<0.05 main effect of rearing, ${ }^{\dagger} p<0.05$ or better, main effect of age.

a

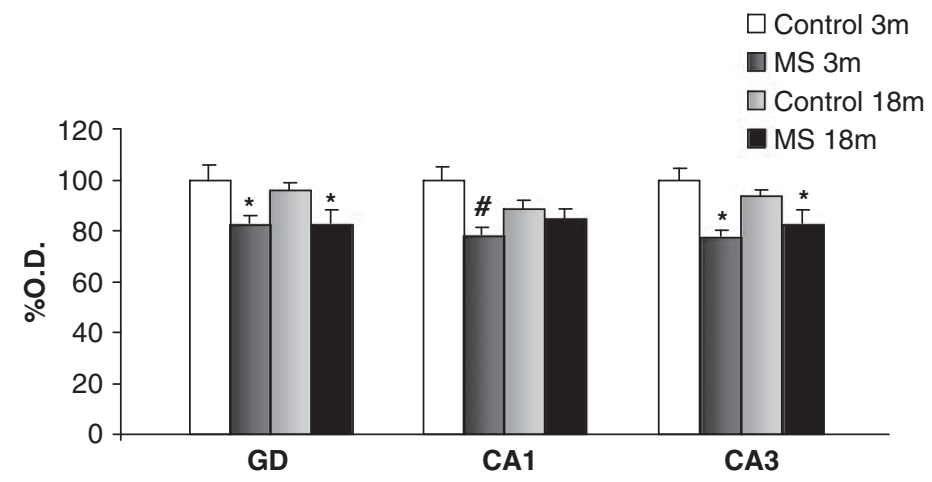

b
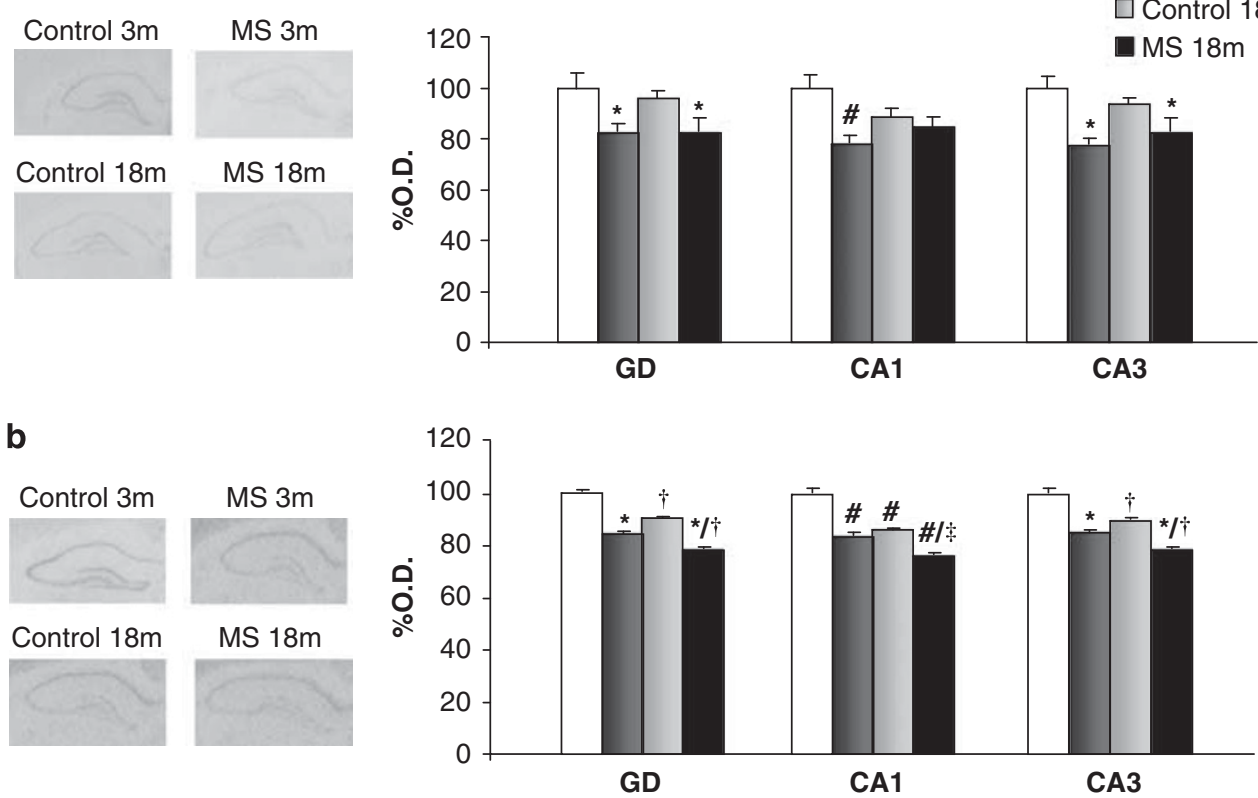

Figure 4 Effects of age and maternal separation (MS) on synaptic plasticity. Figure shows percentage of optical density (O.D.) values of control young rats and representative pictures of autoradiograms. (a) BDNF mRNA expression. (b) ARC mRNA expression. 3 m: 3 months, young rats; and I8 m: 18 months, aged rats. ${ }^{*} p<0.01$ or better, main effect of rearing, two-way ANOVA (rearing $\times$ age), ${ }^{\dagger} p<0.0$ I or better, main effect of age, two-way ANOVA (rearing $\times$ age), ${ }^{\#} p<0.05$ or better vs control young (3 months) rats, ${ }^{\ddagger} p<0.001$ vs MS young ( 3 months) rats or control aged (I 8 months) rats.

note that it is this same route that is required for the induction of long-term potentiation and depression, basic processes underlying learning and memory (Van der Heide et al, 2006). In this regard, clinical and epidemiological studies have found that diabetes and hyperinsulinemia may be suspected factors to increase the risk of developing $\mathrm{AD}$ (Steen $e$ t al, 2005), and it seems that a dysfunction of the IR facilitates tau hyperphosphorylation (Schubert et al, 2004), 
which forms neurofibrillary tangles, through its regulation of GSK3 $\beta$. However, even though according to the reduced input to the IR in aged rats we found a decreased phosphorylation of GSK $3 \beta$, leading to increased activation of the enzyme and subsequent increased phosphorylation of tau, no additive effects of stress were seen.

Insulin binding to IR also activates another signal transduction cascade identified as the MAPK/ERK pathway. ERK1/2 has essential roles in neuronal survival (Xia et al, 1995) and synaptic plasticity related to learning and memory formation (Davis and Laroche, 2006). Furthermore, early work demonstrated an absolute requirement for ERK activity in induction of LTP (English and Sweatt, 1996) and memory consolidation (Eckel-Mahan et al, 2008). Supported by a recent study showing that the microdeletions of the ERK2 gene leads to cognitive deficits (Shaikh et al, 2007), our findings suggest that the ERK2 pathway could be involved in the cognitive deficits observed in aged MS rats, therefore implicating this insulin signaling in the stress-associated memory deficits.

\section{Age and MS Interact to Favor an Increase in Levels of $\mathrm{A} \boldsymbol{\beta}$}

The principal constituent of amyloid plaques observed in $\mathrm{AD}$, is the amyloid $\beta$-protein $(\mathrm{A} \beta)$, which is generated from APP. APP can be cleaved by $\beta$-secretase (BACE1) and $\alpha$-secretase to produce C99 and C83. These C-terminal fragments can then be cleaved by $\gamma$-secretase to produce $\mathrm{A} \beta$ and $\mathrm{p} 3$, respectively. It has been shown that chronic stress or elevated glucocorticoid levels potentiate $\mathrm{A} \beta$ deposition and induces cognitive deficits in transgenic mouse models of AD (Green et al, 2006; Jeong et al, 2006). Glucocorticoids are also able to potentiate hippocampal damage induced by various noxious insults, including the toxic actions of $\mathrm{A} \beta$ (Catania et al, 2009). It has been described that treatment with soluble human $\mathrm{A} \beta$ not only disrupted the activation of ERK and Akt, but also that $\mathrm{A} \beta$ was able to bind to IR, interfering with insulin-induced autophosphorylation (Townsend et al, 2007) or inducing the loss of insulin receptor at the neuronal surface (Zhao et al, 2008; De Felice et al, 2009). C99 has intrinsic neurotoxic properties (Yankner et al, 1989), causes synaptic degeneration (Oster-Granite et al, 1996) and impairs long-term potentiation (Nalbantoglu et al, 1997) and cognition (BergerSweeney et al, 1999), all these effects most probably are due to an enhanced $\mathrm{A} \beta$ generation. In our hands, aging and stress interacts to favor the amyloidogenic route of APP processing, and increased $\mathrm{A} \beta$ formation, probably by upregulating BACE1 levels. A glucocorticoid response element in the promoter region of the BACE1 gene has been described (Sambamurti et al, 2004), making it likely that glucocorticoids mediates the regulatory actions of stress on BACE1 expression by directly increasing transcription of this gene.

On the other hand, the expression of IDE, a metalloprotease that not only catabolises insulin but also has a crucial part in $\mathrm{A} \beta$ clearance in the brain (Kurochkin and Goto, 1994; Qiu et al, 1998), which could be modulated by glucocorticoids (Kulstad et al, 2005). Therefore, in aged MS rats, increases in $A \beta$ due to the increased amyloidogenic route and decreased metabolism by IDE, would interfere

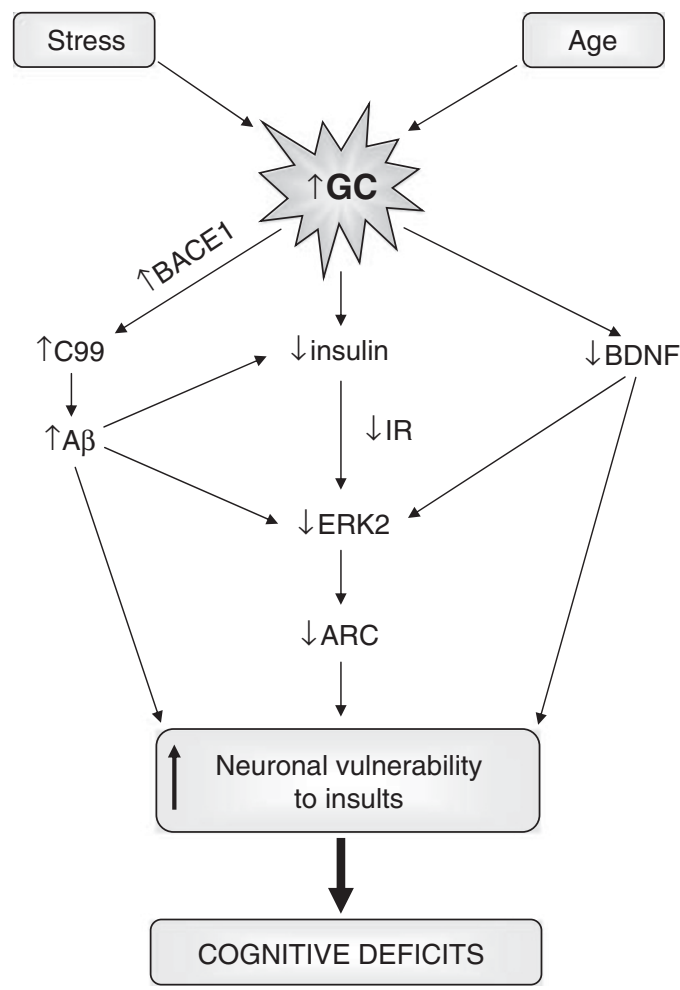

Figure 5 Mechanism through which stress and/or glucocorticoids exerts their effects on aging/Alzheimer's disease (AD). Glucocorticoids by inhibiting the insulin pathway, would lead to a decrease in pERK2 levels, as well as affecting synaptic plasticity. Therefore neuronal ability would be compromised to survive insults, such as increases in glucocorticoid-induced C99 or $\mathrm{A} \beta$ production.

with IR function in hippocampal neurons, preventing the activation of specific kinases (ERK2) required for long term potentiation.

\section{Synaptic Plasticity}

The MS procedure, which took place during critical periods of hippocampal development, can disrupt hippocampal cytoarchitecture in a stable manner (Huot et al, 2002), which may also contribute to the learning deficits observed in adult/aged animals. It is known that different types of stress, including MS (Roceri et al, 2002; Duman and Monteggia, 2006; Warner-Schmidt and Duman, 2006), or increases in $\mathrm{A} \beta$ levels (Christensen et al, 2008) induce reduced BDNF expression. As BDNF signaling activates the ERK1/2 pathway, it could be suggested that the inhibition of ERK cascade in MS aged rats could be related to both a lower BDNF levels and reduced insulin pathways activation. In addition, ARC expression, which is strongly implicated in synaptic plasticity and consolidation of long-term memories (Guzowski et al, 2000), may be up-regulated by BDNF through ERK (Zheng et al, 2009).

\section{CONCLUSION}

Altogether, a tentative mechanism through which stress exert their effects on aging/AD could be suggested based on the present results (Figure 5). Our findings demonstrate that a stress history in the neonatal period exacerbates the 
age-related cognitive decline and therefore, the extent of neonatal exposure to glucocorticoids may determine the extent of age-related cognitive dysfunction (Montaron et al, 2006). It could also be suggested that high levels of glucocorticoids, found in AD (Hartmann et al, 1997; Csernansky et al, 2006; Elgh et al, 2006), might not be merely a consequence of the disease process, but it rather has a central role in the development and progression of the illness. Interactions between endogenous (age, genetics, C99 or $\mathrm{A} \beta$ production) and exogenous factors (stress) might be important determinants of the onset and progress of $\mathrm{AD}$. The present findings suggest that stress management or pharmacological interventions on the glucocorticoids/ insulin pathway warrant additional consideration in the regimen of $\mathrm{AD}$ therapies.

\section{ACKNOWLEDGEMENTS}

This work has been supported by the Newmood integrated project (EC, LSHM-CT-2004-503474) and 'Tu eliges, Tu decides' projects of CAN. Maite Solas has a scholarship from Ministerio de Educación y Ciencia (Spain).

\section{DISCLOSURE}

The authors declare no conflict of interest.

\section{REFERENCES}

Aisa B, Tordera R, Lasheras B, Del Río J, Ramírez MJ (2007). Cognitive impairment associated to HPA axis hyperactivity after maternal separation in rats. Psychoneuroendocrinology 32: 256-266.

Amatruda JM, Livingston JN, Lockwood DH (1985). Cellular mechanisms in selected states of insulin resistance: human obesity, glucocorticoid excess, and chronic renal failure. Diabetes Metab Rev 1: 293-317.

Berger-Sweeney J, McPhie DL, Arters JA, Greenan J, Oster-Granite ML, Neve RL (1999). Impairments in learning and memory accompanied by neurodegeneration in mice transgenic for the carboxyl-terminus of the amyloid precursor protein. Mol Brain Res 66: 150-162.

Berton O, Nestler EJ (2006). New approaches to antidepressant drug discovery: beyond monoamines. Nat Rev Neurosci 7: 137-151.

Born J, Ditschuneit I, Schreiber M, Dodt C, Fehm HL (1995). Effects of age and gender on pituitary-adrenocortical responsiveness in humans. Eur J Endocrinol 132: 705-711.

Brown MW, Aggleton JP (2001). Recognition memory: what are the roles of the perirhinal cortex and hippocampus? Nat Rev Neurosci 2: 51-61.

Catania C, Sotiropoulos I, Silva R, Onofri C, Breen KC, Sousa N et al (2009). The amyloidogenic potential and behavioral correlates of stress. Mol Psychiatry 14: 95-105.

Christensen R, Marcussen AB, Wörtwein G, Knudsen GM, Aznar S (2008). Abeta(1-42) injection causes memory impairment, lowered cortical and serum BDNF levels, and decreased hippocampal 5-HT(2A) levels. Exp Neurol 210: 164-171.

Csernansky JG, Dong H, Fagan AM, Wang L, Xiong C, Holtzman $\mathrm{DM}$ et al (2006). Plasma cortisol and progression of dementia in subjects with Alzheimer-type dementia. Am J Psychiatry 163: 2164-2169.
Davis S, Laroche S (2006). Mitogen-activated protein kinase/ extracellular regulated kinase signaling and memory stabilization: a review. Genes Brain Behav 5: 61-72.

De Felice FG, Vieira MN, Bomfim TR, Decker H, Velasco PT, Lambert MP et al (2009). Protection of synapses against Alzheimer's-linked toxins: insulin signaling prevents the pathogenic binding of Abeta oligomers. Proc Natl Acad Sci USA 106: 1971-1976.

Delaunay F, Khan A, Cintra A, Davani B, Ling ZC, Andersson A et al (1997). Pancreatic beta cells are important targets for the diabetogenic effects of glucocorticoids. J Clin Invest 100: 2094-2098.

Dhikav V, Anand KS (2007). Glucocorticoids may initiate Alzheimer's disease: a potential therapeutic role for mifepristone (RU-486). Med Hypotheses 68: 1088-1092.

Diez-Ariza M, Redondo C, Garcia-Alloza M, Lasheras B, Del Rio J, Ramirez MJ (2003). Flumazenil and tacrine increase the effectiveness of ondansetron on scopolamine-induced impairment of spatial learning in rats. Psychopharmacology 169: 35-41.

Duman RS, Monteggia LM (2006). A neurotrophic model for stress-related mood disorders. Biol Psychiatry 59: 1116-1127.

Dupont J, LeRoith D (2001). Insulin and insulin-like growth factor I receptors: similarities and differences in signal transduction. Horm Res 55: 22-26.

Eckel-Mahan KL, Phan T, Han S, Wang H, Chan GC, Scheiner ZS et al. (2008). Circadian oscillation of hippocampal MAPK activity and cAMP: implications for memory persistence. Nat Neurosci 11: 1074-1082.

Elgh E, Lindqvist Astot A, Fagerlund M, Eriksson S, Olsson T, Näsman B (2006). Cognitive dysfunction, hippocampal atrophy and glucocorticoid feedback in Alzheimer's disease. Biol Psychiatry 59: 155-161.

English JD, Sweatt JD (1996). Activation of p42 mitogen-activated protein kinase in hippocampal long term potentiation. J Biol Chem 271: 24329-24332.

Green KN, Billings LM, Roozendaal B, McGaugh JL, LaFerla FM (2006). Glucocorticoids increase amyloid-beta and tau pathology in a mouse model of Alzheimer's disease. J Neurosci 26: 9047-9056.

Guzowski JF, Lyford GL, Stevenson GD, Houston FP, McGaugh JL, Worley PF et al (2000). Inhibition of activity-dependent arc protein expression in the rat hippocampus impairs the maintenance of long-term potentiation and the consolidation of long-term memory. J Neurosci 20: 3993-4001.

Hartmann A, Veldhuis JD, Deuschle M, Standhardt H, Heuser I (1997). Twenty-four hour cortisol release profiles in patients with Alzheimer's and Parkinson's disease compared to normal controls: ultradian secretory pulsatility and diurnal variation. Neurobiol Aging 18: 285-289.

Hauger RL, Thrivikraman KV, Plotsky PM (1994). Age-related alterations of hypothalamic-pituitary-adrenal axis function in male Fischer 344 rats. Endocrinology 134: 1528-1536.

Heim C, Nemeroff CB (1999). The impact of early adverse experiences on brain systems involved in the pathophysiology of anxiety and affective disorders. Biol Psychiatry 46: 1509-1522.

Heim C, Nemeroff CB (2001). The role of childhood trauma in the neurobiology of mood and anxiety disorders: preclinical and clinical studies. Biol Psychiatry 49: 1023-1039.

Huot RL, Plotsky PM, Lenox RH, McNamara RK (2002). Neonatal maternal separation reduces hippocampal mossy fiber density in adult Long Evans rats. Brain Res 950: 52-63.

Jeong YH, Park CH, Yoo J, Shin KY, Ahn SM, Kim HS et al (2006). Chronic stress accelerates learning and memory impairments and increases amyloid deposition in APPV717I-CT100 transgenic mice, an Alzheimer's disease model. FASEB J 20: 729-731.

Kendler KS, Karkowski LM, Prescott CA (1999). Causal relationship between stressful life events and the onset of major depression. Am J Psychiatry 156: 837-841. 
Kulstad JJ, McMillan PJ, Leverenz JB, Cook DG, Green PS, Peskind ER et al (2005). Effects of chronic glucocorticoid administration on insulin-degrading enzyme and amyloid-beta peptide in the aged macaque. J Neuropathol Exp Neurol 64: 139-146.

Kurochkin IV, Goto S (1994). Alzheimer's $\beta$-amyloid peptide specifically interacts with and is degraded by insulin degrading enzyme. FEBS Lett 345: 33-37.

Ladd CO, Huot RL, Thrivikraman KV, Nemeroff CB, Meaney MJ, Plotsky PM (2000). Long-term behavioral and neuroendocrine adaptations to adverse early experience. Prog Brain Res 122: 81-103.

Ladd CO, Huot RL, Thrivikraman KV, Nemeroff CB, Plotsky PM (2004). Long-term adaptations in glucocorticoid receptor and mineralocorticoid receptor mRNA and negative feedback on the hypothalamo-pituitary-adrenal axis following neonatal maternal separation. Biol Psychiatry 55: 367-375.

Lambillotte C, Gilon P, Henquin JC (1997). Direct glucocorticoid inhibition of insulin secretion: an in vitro study of dexamethasone effects in mouse islets. J Clin Invest 99: 414-423.

Lehmann J, Feldon J (2000). Long-term biobehavioral effects of maternal separation in the rat: consistent or confusing? Rev Neurosci 11: 383-408.

Lupien SJ, de Leon M, de Santi S, Convit A, Tarshish C, Nair NP et al (1998). Cortisol levels during human aging predict hippocampal atrophy and memory deficits. Nat Neurosci 1: 69-73.

Magariños AM, McEwen BS (2000). Experimental diabetes in rats causes hippocampal dendritic and synaptic reorganization and increased glucocorticoid reactivity to stress. Proc Natl Acad Sci USA 97: 11056-11061.

McEwen BS (2002). Sex, stress and the hippocampus: allostasis, allostatic load and the aging process. Neurobiol Aging 23: 921-939.

Miller DB, O'Callaghan JP (2005). Aging, stress and the hippocampus. Ageing Res Rev 4: 123-140.

Montaron MF, Drapeau E, Dupret D, Kitchener P, Aurousseau C, Le Moal M et al (2006). Lifelong corticosterone level determines age-related decline in neurogenesis and memory. Neurobiol Aging 27: 645-654.

Nalbantoglu J, Tirado-Santiago G, Lahsaini A, Poirier J, Goncalves O, Verge $G$ et al (1997). Impaired learning and LTP in mice expressing the carboxy terminus of the Alzheimer amyloid precursor protein. Nature 387: 500-505.

Oitzl MS, Workel JO, Fluttert M, Frösch F, De Kloet ER (2000). Maternal deprivation affects behaviour from youth to senescence: amplification of individual differences in spatial learning and memory in senescent Brown Norway rats. Eur J Neurosci 12: 3771-3780.

Oster-Granite ML, McPhie DL, Greenan J, Neve RL (1996). Agedependent neuronal and synaptic degeneration in mice transgenic for the $\mathrm{C}$ terminus of the amyloid precursor protein. J Neurosci 16: 6732-6741.

Ownby RL, Crocco E, Acevedo A, John V, Loewenstein D (2006). Depression and risk for Alzheimer disease: systematic review, meta-analysis, and metaregression analysis. Arch Gen Psychiatry 63: $530-538$

Paxinos G, Watson C (1982). The Rat Brain in Stereotaxic Coordinates. Academic Press: San Diego.

Porsolt RD, Le Pichon M, Jalfre M (1977). Depression: a new animal model sensitive to antidepressant treatments. Nature 266: 730-732.

Qiu WQ, Walsh DM, Ye Z, Vekrellis K, Zhang J, Podlisny MB et al (1998). Insulin-degrading enzyme regulates extracellular levels of amyloid $\beta$-protein by degradation. J Biol Chem 273: 32730-32738.

Roceri M, Hendriks W, Racagni G, Ellenbroek BA, Riva A (2002). Early maternal deprivation reduces the expression of BDNF and
NMDA receptor subunits in rat hippocampus. Mol Psychiatry 7: 609-616.

Sambamurti K, Kinsey R, Maloney B, Ge YW, Lahiri DK (2004). Gene structure and organization of the human beta-secretase (BACE) promoter. FASEB J 18: 1034-1036.

Sapolsky RM, Krey LC, McEwen BS (1983). The adrenocortical stress-response in the aged male rat: impairment of recovery from stress. Exp Gerontol 18: 55-64.

Sapolsky RM (1985). Glucocorticoid toxicity in the hippocampus: temporal aspects of neuronal vulnerability. Brain Res 359: 300-305.

Sapolsky RM, Pulsinelli WA (1985). Glucocorticoids potentiate ischemic injury to neurons: therapeutic implications. Science 229: $1397-1400$

Sapolsky RM, Krey LC, McEwen BS (1986). The neuroendocrinology of stress and aging: the glucocorticoid cascade hypothesis. Endocr Rev 7: 284-301.

Sapolsky RM, Meaney MJ (1986). Maturation of the adrenocortical stress response: neuroendocrine control mechanisms and the stress hyporesponsive period. Brain Res 396: 64-76.

Schubert M, Gautam D, Surjo D, Ueki K, Baudler S, Schubert D et al (2004). Role for neuronal insulin resistance in neurodegenerative diseases. Proc Natl Acad Sci USA 101: 3100-3105.

Shaikh TH, O'Connor RJ, Pierpont ME, McGrath J, Hacker AM, Nimmakayalu $M$ et al (2007). Low copy repeats mediate distal chromosome 22q11.2 deletions: sequence analysis predicts breakpoint mechanisms. Genome Res 17: 482-491.

Steen E, Terry BM, Rivera EJ, Cannon JL, Neely TR, Tavares R et al (2005). Impaired insulin and insulin-like growth factor expression and signaling mechanisms in Alzheimer's disease-is this type 3 diabetes? J Alzheimers Dis 7: 63-80.

Stranahan AM, Arumugam TV, Cutler RG, Lee K, Egan JM, Mattson MP (2008). Diabetes impairs hippocampal function through glucocorticoid-mediated effects on new and mature neurons. Nat Neurosci 11: 309-317.

Townsend M, Mehta T, Selkoe DJ (2007). Soluble Abeta inhibits specific signal transduction cascades common to the insulin receptor pathway. J Biol Chem 282: 33305-33312.

Van der Heide LP, Ramakers GM, Smidt MP (2006). Insulin signaling in the central nervous system: learning to survive. Prog Neurobiol 79: 205-221.

Warner-Schmidt JL, Duman RS (2006). Hippocampal neurogenesis: opposing effects of stress and antidepressant treatment. Hippocampus 16: 239-249.

Wigger A, Neumann ID (1999). Periodic maternal deprivation induces gender-dependent alterations in behavioral and neuroendocrine responses to emotional stress in adult rats. Physiol Behav 66: 293-302.

Wilson RS, Barnes LL, Bennett DA, Li Y, Bienias JL, Mendes de Leon CF et al (2005). Proneness to psychological distress and risk of Alzheimer disease in a biracial community. Neurology 64: 380-382.

Xia Z, Dickens M, Raingeaud J, Davis RJ, Greenberg ME (1995). Opposing effects of ERK and JNK-p38 MAP kinases on apoptosis. Science 270: 1326-1331.

Yankner BA, Dawes LR, Fisher S, Villa-Komaroff L, Oster-Granite ML et al (1989). Neurotoxicity of a fragment of the amyloid precursor associated with Alzheimer's disease. Science 245: 417-420.

Zhao WQ, De Felice FG, Fernandez S, Chen H, Lambert MP, Quon MJ et al (2008). Amyloid beta oligomers induce impairment of neuronal insulin receptors. FASEB J 22: 246-260.

Zheng F, Luo Y, Wang H (2009). Regulation of brain-derived neurotrophic factor-mediated transcription of the immediate early gene Arc by intracellular calcium and calmodulin. J Neurosci Res 87: 380-392. 